\title{
Inhibition of angiotensin-converting enzyme by selenoneine
}

\author{
Takuya Seko $^{1} \cdot$ Shintaro Imamura ${ }^{1} \cdot$ Kenji Ishihara $^{1} \cdot$ Yumiko Yamashita ${ }^{1} \cdot$ Michiaki Yamashita $^{2}$
}

Received: 4 February 2019 / Accepted: 17 April 2019 / Published online: 20 May 2019

(c) The Author(s) 2019

\begin{abstract}
Selenoneine is a selenium-containing compound that exhibits strong radical-scavenging activity. Here we present a novel function of selenium in which selenoneine exhibits inhibitory activity against angiotensin-converting enzyme (ACE). ACE activity was strongly inhibited by selenoneine as compared to a typical peptide that decreases blood pressure in vitro. Kinetics analysis suggested that selenoneine inhibits ACE by competitive inhibition via the binding of selenoneine to zinc in the active center of ACE.
\end{abstract}

Keywords Selenium $\cdot$ Metalloprotease $\cdot$ Enzyme kinetics $\cdot$ Competitive inhibition

\section{Introduction}

Selenoneine is a novel selenium-containing imidazole found in the blood of tuna (Fig. 1). This compound is a selenium analog of ergothioneine, which is known to be an antioxidant, and has stronger radical-scavenging activity than ergothioneine (Yamashita and Yamashita 2010). These compounds are incorporated into cells via the organic cation/ carnitine transporter-1 (OCTN1) (Gründemann et al. 2005; Yamashita et al. 2013a). Thus, it has been suggested that selenoneine accumulates in the tissues that express OCTN1. Moreover, erythrocytes with high levels of selenoneine have

Michiaki Yamashita

mic@fish-u.ac.jp

Takuya Seko

sekotakuya@affrc.go.jp

Shintaro Imamura

sintaroi@affrc.go.jp

Kenji Ishihara

hplc@affrc.go.jp

Yumiko Yamashita

ymk0125@affrc.go.jp

1 National Research Institute of Fisheries Science, Kanazawa,

Yokohama, Kanagawa 236-8648, Japan

2 Department of Food Science and Technology, National Fisheries University, Shiminoseki, Yamaguchi 759-6595, Japan been reported in people who often eat fish (Yamashita et al. 2013b).

It has been previously reported that selenoneine can bind to and detoxify methylmercury $(\mathrm{MeHg})$ by accelerating the excretion and demethylation of $\mathrm{MeHg}$ via secretory extracellular lysosomal vesicles that are found in animal cells and tissues (Yamashita et al. 2013b). These findings suggest that selenoneine can bind to mercury as well as other metals. Banerjee et al. (2015) reported that selones, members of a group that includes selenium, could detoxify organic mercurial compounds. Selones have also been shown to react to metal halides such as copper(I) bromide and zinc chloride to form complexes (Yadav et al. 2017). Furthermore, it has also been suggested that selenoneine is able to react to the metal ion in a metalloenzyme.

Angiotensin-converting enzyme (ACE; EC 3.4.15.1), a zinc metalloprotease, is a component of the renin-angiotensin-aldosterone system. It catalyzes cleavage of the C-terminal dipeptide from angiotensin I to produce angiotensin II. This potent octapeptide plays a role in the elevation of blood pressure (Skeggs et al. 1956; Vickers et al. 2002).

The ACE inhibitors captopril and enalapril are used as antihypertensive medicines (Ondetti et al. 1977; Ferguson et al. 1982; Reynolds et al. 1984). Captopril attaches to the active center of ACE by direct interaction of its thiol group with the catalytic zinc ion of ACE (Natesh et al. 2004). ACE inhibitory polypeptides can be produced from hydrolysates of fish such as sardines, in addition to also being used as source materials for functional foods and supplements 


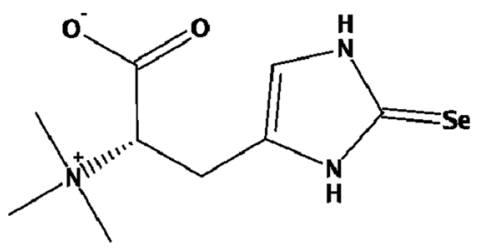

b

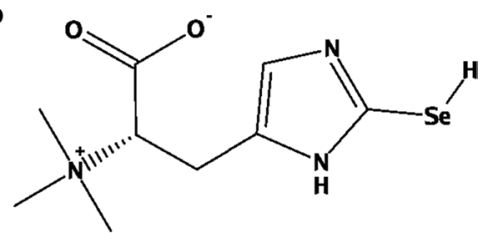

Fig. 1 Structures of selenoneine. Selenoneine changes its structure by the tautomerization of selenoxo-selenol depending on the surrounding conditions. a Selenoxo form. b Selenol form

(Matsufuji et al. 1994). Moreover, seleno-captopril, the selenium analog of captopril, has been reported to inhibit ACE activity via the interaction of the selenol group with the zinc ion, similar to that seen in captopril (Bhuyan et al. 2011; Akif et al. 2011). A recent study has further confirmed that the selenol group does bind to the zinc ion (Banerjee et al. 2015). Therefore, we speculated that selenoneine might also be able to bind to metal ions and inhibit metalloenzymes.

This study characterized the inhibitory effect of selenoneine on ACE activity based on in vitro enzymatic experiments. Enzyme kinetics revealed the type of inhibition of ACE by selenoneine. Moreover, in silico study predicted the location and molecular interactions of selenoneine at the active center of ACE.

\section{Materials and methods}

\section{Materials}

Selenoneine was extracted from tuna and purified by high performance liquid chromatography in accordance with the method of Yamashita and Yamashita (2010). Selenoneine was then dissolved in Milli-Q water, with the solution adjusted to $\mathrm{pH} 6.8$ using sodium hydroxide, and stored at $4{ }^{\circ} \mathrm{C}$. Lung acetone powder from rabbit, $N$-hippuryl-L-histidyl-L-leucine hydrate (HHL), hippuric acid, L-valyl-L-tyrosine (Val-Tyr) and ergothioneine were all purchased from Sigma-Aldrich (MO, USA). Purified bovine lung ACE was purchased from Life Laboratory (Yamagata, Japan). Sodium selenite was purchased from Wako Pure Chemical Industries (Osaka, Japan).

\section{Enzyme solutions}

The substrate solution consisted of $7.6 \mathrm{mM}$ HHL in $200 \mathrm{mM}$ borate buffer at $\mathrm{pH} 8.3$, and contained $608 \mathrm{mM}$ sodium chloride. To extract $\mathrm{ACE}$ from rabbit lung acetone powder, the powder $(1.0 \mathrm{~g})$ was homogenized in $10 \mathrm{ml}$ of $200 \mathrm{mM}$ borate buffer at $4{ }^{\circ} \mathrm{C}$, and then centrifuged at $17,700 \mathrm{~g}$ for $10 \mathrm{~min}$ at $4{ }^{\circ} \mathrm{C}$. The supernatant was collected and diluted by a factor of 5 using $200 \mathrm{mM}$ borate buffer, and then used as the rabbit ACE solution. Purified bovine lung ACE was dissolved in $200 \mathrm{mM}$ borate buffer $(0.1 \mathrm{unit} / \mathrm{ml})$, and then used as the bovine ACE solution. Inhibitor solution was made by dissolving Val-Tyr, selenoneine, ergothioneine and selenite in Milli-Q water.

\section{Measurement of ACE activity}

ACE activity was measured using the method of Maruyama et al. (1987) with some modifications. An aliquot containing $30 \mu \mathrm{l}$ of inhibitor solution and $250 \mu \mathrm{l}$ of substrate solution was pre-incubated at $37{ }^{\circ} \mathrm{C}$ for $5 \mathrm{~min}$. Subsequently, $100 \mu \mathrm{l}$ of rabbit ACE solution was added to the aliquot, followed by incubation at $37{ }^{\circ} \mathrm{C}$ for $20 \mathrm{~min}$. To stop the reaction, $250 \mu \mathrm{l}$ of $1 \mathrm{M} \mathrm{HCl}$ was added to the reaction mixture. To extract hippuric acid, the product of this reaction, $1.5 \mathrm{ml}$ of ethyl acetate was added to the solution, mixed and then centrifuged at $1750 \mathrm{~g}$ at $4{ }^{\circ} \mathrm{C}$ for $10 \mathrm{~min}$, with $1.0 \mathrm{ml}$ of the supernatant then collected. After completely desiccating the supernatant using a centrifugal evaporator, it was then diluted with $4 \mathrm{ml}$ of Milli-Q water and used as the extracted hippuric acid solution. Hippuric acid was detected at an absorbance of $228 \mathrm{~nm}$.

\section{Kinetics studies}

The kinetics of ACE with selenoneine were measured using bovine lung ACE. ACE activity was measured as per the above described method. The substrate solution was adjusted to a final concentration of $0.659-5.27 \mathrm{mM}$ using a twofold serial dilution. Selenoneine was added to the reaction mixture to a final concentration of $0.5 \mu \mathrm{M}$. The reaction velocity was calculated based on the amount of hippuric acid produced, which was quantified by a standard curve. Kinetic analysis was based on the Michaelis-Menten equation calculated by GraphPad Prism version 6 for Windows (GraphPad Software, CA, USA).

\section{Docking simulation}

A docking study was performed using selenoneine to examine the binding poses against human ACE. The crystal structure of ACE was obtained from the Protein Data Bank 
[identifier (ID) 2YDM] and used as the target structure for the docking study. This crystal structure was imported into the docking simulation software, Molecular Operating Environment (MOE; Chemical Computing Group, Montreal, Canada). Each of the selenoneine forms (Fig. 1) was drawn using the builder module in the MOE software. ACE and selenoneine were prepared for docking using the Quick Prep command, and then charged and minimized under the AMBER 10 EHT force field in the MOE software.

\section{Statistical analysis}

Values are expressed as mean \pm SD. Data were analyzed by one-way ANOVA with Tukey's multiple comparison test to identify any significant differences $(P<0.05)$ with GraphPad Prism version 6 for Windows.

\section{Results}

\section{Inhibitory effect of selenoneine on ACE activity}

The inhibition of rabbit lung ACE activity by the ACE inhibitor peptides and selenoneine was measured by the release of hippuric acid from the substrate peptide. Val-Tyr, which was

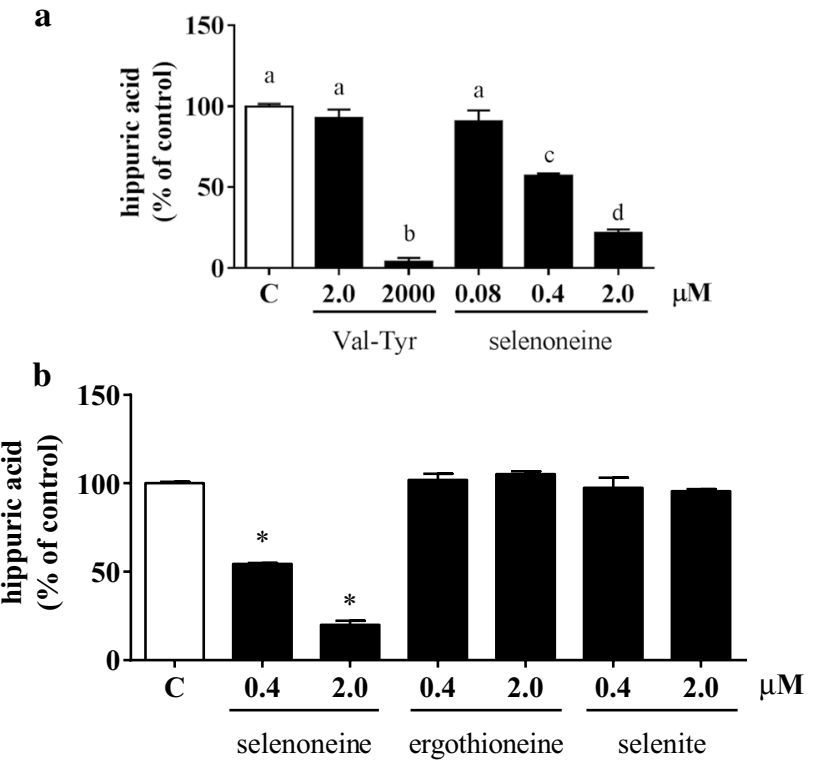

Fig. 2 Comparisons of the inhibitory effects of selenoneine and other compounds on rabbit angiotensin-converting enzyme (ACE) activity. a Inhibitory effect of L-valyl-L-tyrosine and selenoneine against rabbit ACE. White bar: Value of the control $(C)$ group. Values are mean \pm SD of three replicates. Values with different letters are significantly different $(P<0.05)$. b Inhibitory effect of selenoneine, ergothioneine and selenite. Values are mean $\pm \mathrm{SD}$ of three replicates. Asterisks indicate significant differences between groups $(P<0.05$; Tukey's multiple comparison test) added as the ACE inhibitory peptide, inhibited ACE activity at more than $2000 \mu \mathrm{M}$. Selenoneine dose-dependently inhibited ACE activity at 0.4 and $2.0 \mu \mathrm{M}$ (Fig. 2a). ACE activity was not inhibited by ergothioneine and selenite at $2.0 \mu \mathrm{M}$ (Fig. 2b).

\section{Kinetic study of ACE inhibition by selenoneine}

Based on the enzyme kinetics, the $V_{\max }$ values were $4.27 \pm 0.25 \mathrm{nmol} / \mathrm{min}$ and $4.22 \pm 0.14 \mathrm{nmol} / \mathrm{min}$, while the $K_{\mathrm{m}}$ values were $1.45 \pm 0.12 \mathrm{mM}$ and $0.63 \pm 0.04 \mathrm{mM}$ with or without selenoneine, respectively, in the experiment with purified bovine ACE (Table 1; Fig. 3). Although the $K_{\mathrm{m}}$ value in the presence of selenoneine was significantly higher than that observed in the absence of selenoneine $(P<0.01)$, there was no change in the $V_{\max }$ values between the two groups. These results indicate that selenoneine acts via competitive inhibition.

\section{Docking simulation study}

In the docking simulation study, selenoneine was located in the active center of ACE. Different results were found for the selenoxo and selenol forms of selenoneine. The selenoxo form (Fig. 1a) bound to the zinc ion (Zn1619) in ACE via the oxygen in the carbonyl group. The distance between the zinc

Table $1 V_{\max }$ and $K_{\mathrm{m}}$ values of control and selenoneine-addition groups

\begin{tabular}{lll}
\hline Sample & $V_{\max }(\mathrm{nmol} / \mathrm{min})$ & $K_{\mathrm{m}}(\mathrm{mM})$ \\
\hline Control & $4.22 \pm 0.14$ & $0.63 \pm 0.04$ \\
Selenoneine & $4.27 \pm 0.25$ & $1.45 \pm 0.12^{*}$ \\
\hline
\end{tabular}

Inhibition of selenoneine against bovine ACE was measured. Values are mean \pm SD of three replicates

$* P<0.05$ (Student's $t$-test)

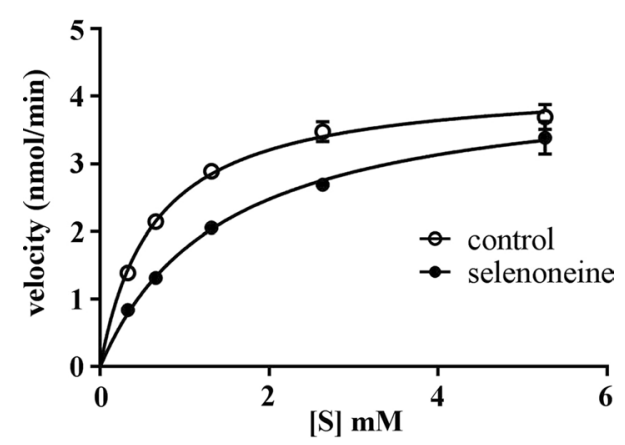

Fig. 3 Kinetic analysis of ACE with or without selenoneine. Activity of bovine ACE in the presence of selenoneine. Velocity was calculated from the amount of hippuric acid produced per minute. Values are mean \pm SD of three replicates 


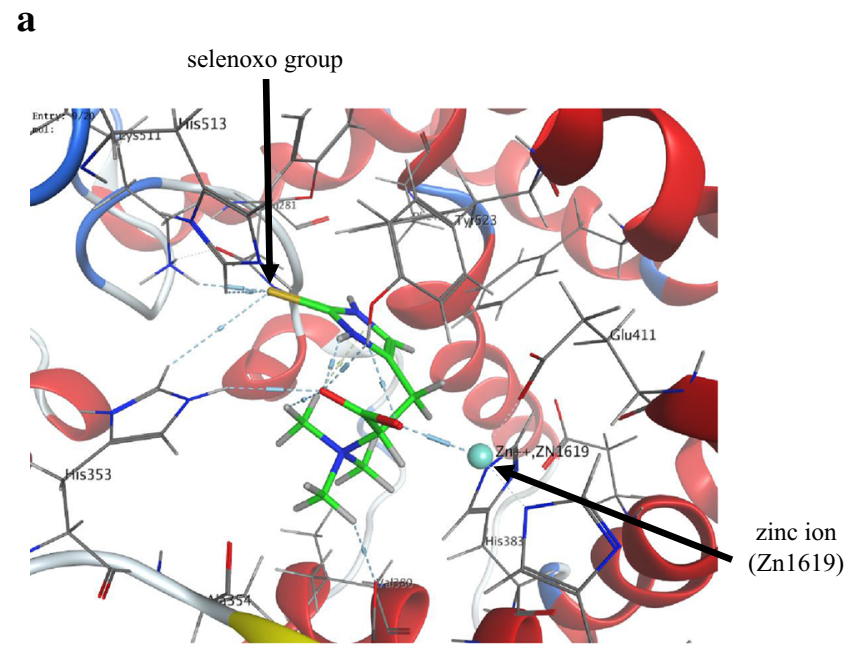

b

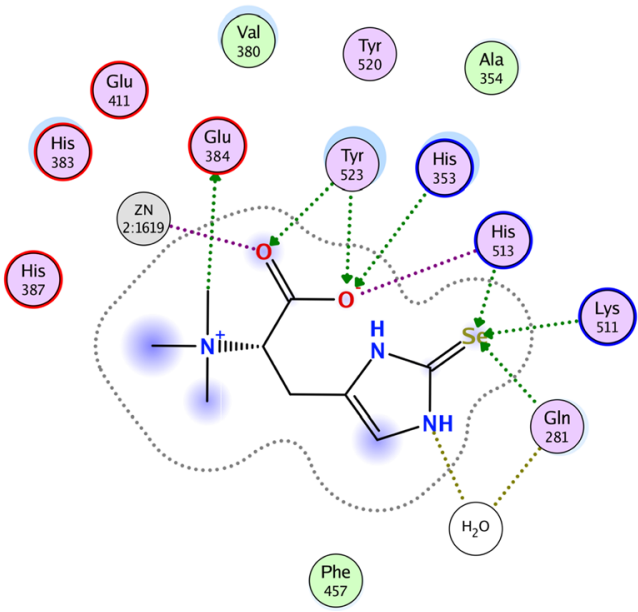

Fig. 4 Results of the in silico molecular docking simulation study. a One of the stable positions and structures of selenoneine, the selenoxo form (docking score of $-25.2 \mathrm{~kJ} / \mathrm{mol}$ ) at the active center of ACE (identifier 2YDM). b Protein-ligand interaction of this simulation. $\mathbf{c}, \mathbf{d}$ Results of the simulation for the selenol form of selenoneine (docking score $-21.2 \mathrm{~kJ} / \mathrm{mol}$ ). Purple dotted line indicates metal or ion contact. Green dotted line indicates side chain proton acceptor/ donor. Amino acids circled in blue are basic amino acids; amino acids

and the oxygen was $0.221 \mathrm{~nm}$. In this model, the selenoxo group interacted as a proton acceptor with glutamine (Gln281), lysine (Lys-511) and histidine (His-513). The distances between the selenium and these amino acids were $0.326,0.318$ and $0.339 \mathrm{~nm}$, respectively (Fig. 4a, b). For this simulation, the docking score, which is the score of the affinity of a ligand and an enzyme, was $-25.23 \mathrm{~kJ} / \mathrm{mol}$. In contrast, the selenol form (Fig. 1b) interacted with other amino acids and did not bind to the zinc ion. The oxygen of the carboxyl group of selenoneine interacted with the lysine (Lys-511) and histidine (His-513) as a proton acceptor. The selenol group interacted as a proton donor with aspartic acid (Fig. 4c, d). For this simulation, the docking score was $-21.21 \mathrm{~kJ} / \mathrm{mol}$.

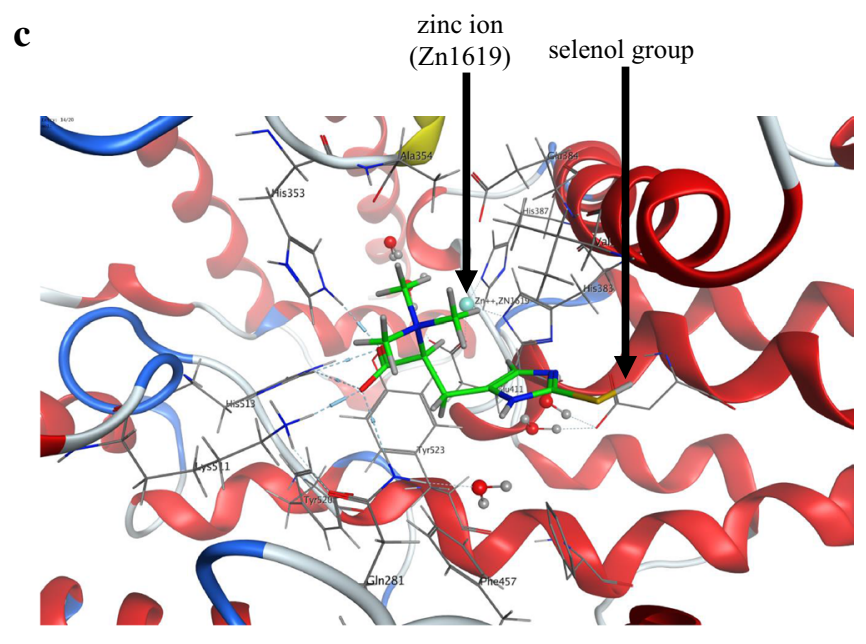

d

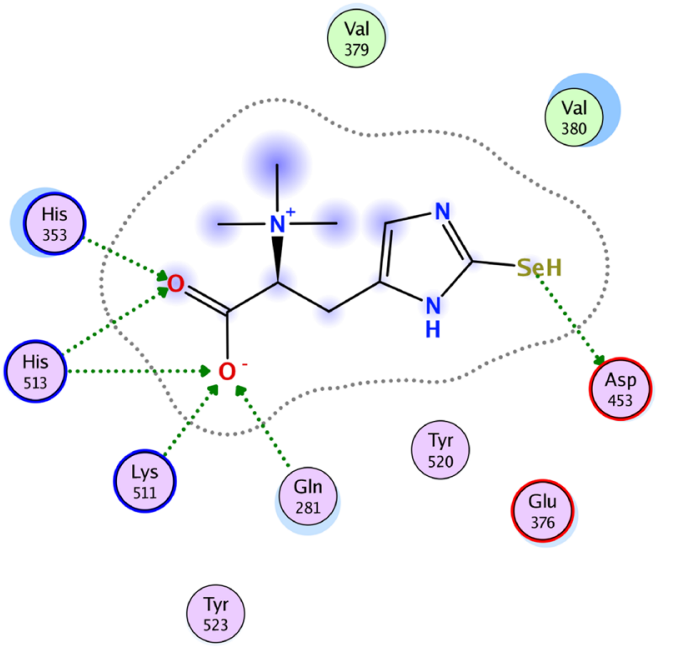

circled in red are acidic amino acids. Background disks behind certain amino acids, e.g., Tyr-523 in (a), denote their solvent exposure. Blue shading behind certain ligand atoms also denotes their solvent exposure. Amino acids or ligand atoms with larger background disks or deeper shading were more exposed to solvent. Pictures and figures were predicted and described with MOE software (color figure online)

\section{Discussion}

This study demonstrates that selenoneine inhibited ACE activity via competitive inhibition. The in silico docking simulation indicated that selenoneine inhibited ACE via the interaction between selenoneine and the zinc ion, namely stable selenoneine in the active center of ACE prevents the substrate from binding to ACE.

Previous studies have reported that some other peptides can also inhibit ACE activity. One of these, Val-Tyr, is found in the alkaline protease hydrolysate of sardine muscle. It inhibits ACE activity at a half maximal inhibitory concentration $\left(\mathrm{IC}_{50}\right)$ of $26.0 \mu \mathrm{M}$ (Matsufuji et al. 1995). Selenoneine 
inhibited ACE activity more strongly than Val-Tyr, with an $\mathrm{IC}_{50}$ value of $0.72 \mu \mathrm{M}$ (Fig. 2a). Ergothioneine, which is a thiol analog of selenoneine, and selenite did not inhibit ACE activity (Fig. 2b). These results suggest that the selenoxo group of selenoneine is associated with the inhibition of ACE. Since the properties of the selenoxo group resemble those of the thiol group, we predicted that selenoneine would inhibit ACE in a similar way to that observed for some thiols like captopril. To clarify this, we conducted kinetic studies designed to elucidate how selenoneine inhibited ACE. The $V_{\max }$ values did not differ between the groups with or without selenoneine. In contrast, there were significantly different $K_{\mathrm{m}}$ values between these two groups (Table 1). These results demonstrate that the inhibition of ACE by selenoneine is competitive. In general, the $K_{i}$ value is calculated to determine the potential inhibition of an inhibitor. Dixon's $(1953,1972)$ method to determine the $K_{i}$ value requires a large amount of selenoneine transiting stepwise from a low to high density. In the current study, the $K_{i}$ value, $0.37 \pm 0.09 \mu \mathrm{M}$, was calculated by using the $K_{\mathrm{m}}$ values of the control group and the selenoneine-added group that were based on the enzyme kinetics in the presence of a competitive inhibitor $\left\{K_{\mathrm{m}_{\text {control }}}=K_{\mathrm{m}_{\text {selenoneine }}}\left(1+[I] / K_{i}\right)\right\}$.

Previous studies have reported that seleno-captopril, a selenium analog of captopril, inhibits ACE (Bhuyan et al. 2011; Akif et al. 2011). Captopril is a well-known ACE inhibitor; its thiol group chelates the catalytic zinc ion of ACE, thereby prevents substrates like angiotensin I from being cleaved (Natesh et al. 2004). Furthermore, it has also been reported that seleno-captopril inhibits ACE in the same way as reported for captopril (Akif et al. 2011). On the basis of these previous studies and our current results, we speculated that selenoneine also inhibits ACE via the chelation of the zinc ion through the selenoxo group. To test this hypothesis, we conducted an in silico docking simulation, which can predict the locations, forms and styles of small molecules by using enzymes. In this study, ACE was described based on the crystallography of the testis ACE with selenocaptopril from the Protein Data Bank (ID 2YDM). The simulation results showed that, although selenoneine was located at the active center of ACE, selenium did not chelate the zinc ion. However, the oxygen in the carbonyl group chelated the zinc ion and the selenoxo group interacted with several amino acids (glutamine, lysine and histidine; Fig. 4b) as a proton acceptor. Figure $4 \mathrm{c}$, d shows the simulation results when selenoneine is the selenol form in the active center of ACE. We considered these results as reference findings since selenoneine exists in the selenoxo form in the physiological condition (Yamashita and Yamashita 2010). Based on these findings, we speculated that these interactions contributed to both the stability of selenoneine in the enzyme and the inhibitory effect.
The present findings also suggest that the inhibition of ACE in human and animals might be a means of preventing hypertension in vivo. Thus, it is necessary to characterize the inhibition of ACE in vivo in conjunction with selenoneine intake. Results of a previous epidemiological study supported the prevention of hypertension due to selenium intake from seafood (Xun et al. 2011). Thus, food that contains selenoneine from fish, and other foods containing selenoneine, could very well contribute to the lowering of blood pressure and the prevention of hypertension. In addition, the findings that selenoneine exhibited interactions and has zinc-chelating abilities suggest that selenoneine may bind and inhibit other metalloenzymes, such as matrix metalloproteases and several cytochrome P450s.

In conclusion, this study found a novel biochemical function of selenium in the inhibition of ACE activity by selenoneine. The results suggest that selenoneine might bind to the zinc ion at the active center of the enzyme.

Acknowledgement This work was supported by grants from the National Research Institute of Fisheries Science, Japan.

Open Access This article is distributed under the terms of the Creative Commons Attribution 4.0 International License (http://creativeco mmons.org/licenses/by/4.0/), which permits unrestricted use, distribution, and reproduction in any medium, provided you give appropriate credit to the original author(s) and the source, provide a link to the Creative Commons license, and indicate if changes were made.

\section{References}

Akif M, Masuyer G, Schwager SL, Bhuyan BJ, Mugesh G, Isaac RE, Sturrock ED, Acharya KR (2011) Structural characterization of angiotensin I-converting enzyme in complex with a selenium analogue of captopril. FEBS J 278:3644-3650

Banerjee M, Karri R, Rawat KS, Muthuvel K, Pathak B, Roy G (2015) Chemical detoxification of organomercurials. Angew Chem Int Ed Engl 127:9455-9459

Bhuyan BJ, Mugesh G (2011) Effect of peptide-based captopril analogues on angiotensin converting enzyme activity and peroxynitrite-mediated tyrosine nitration. Org Biomol Chem 9:5185-5192

Dixon M (1953) The determination of enzyme inhibitor constants. Biochem J 55:170

Dixon M (1972) The graphical determination of $K_{\mathrm{m}}$ and $K_{i}$. Biochem J 129:197-202

Ferguson RK, Vlasses PH, Swanson BN, Mojaverian P, Hichens M, Irvin JD, Huber PB (1982) Effects of enalapril, a new converting enzyme inhibitor, in hypertension. Clin Pharmacol Ther 32:48-53

Gründemann D, Harlfinger S, Golz S, Geerts A, Lazar A, Berkels R, Jung N, Rubbert A, Schömig E (2005) Discovery of the ergothioneine transporter. Proc Natl Acad Sci USA 102:5256-5261

Maruyama S, Mitachi H, Awaya J, Kurono M, Tomizuka N, Suzuki H (1987) Angiotensin I-converting enzyme inhibitory activity of the C-terminal hexapeptide of $\alpha$ s1-casein. Agric Biol Chem $51: 2557-2561$

Matsufuji H, Matsui T, Seki E, Osajima K, Nakashima M, Osajima Y (1994) Angiotensin I-converting enzyme inhibitory peptides in an alkaline protease hydrolyzate derived from sardine muscle. Biosci Biotechnol Biochem 58:2244-2245 
Matsufuji H, Matsui T, Ohshige S, Kawasaki T, Osajima K, Osajima Y (1995) Antihypertensive effects of angiotensin fragments in SHR. Biosci Biotechnol Biochem 59:1398-1401

Natesh R, Schwager SL, Evans HR, Sturrock ED, Acharya KR (2004) Structural details on the binding of antihypertensive drugs captopril and enalaprilat to human testicular angiotensin I-converting enzyme. Biochemistry 43:8718-8724

Ondetti MA, Rubin B, Cushman DW (1977) Design of specific inhibitors of angiotensin-converting enzyme: new class of orally active antihypertensive agents. Science 196:441-444

Reynolds CH (1984) Kinetics of inhibition of angiotensin converting enzyme by captopril and by enalapril diacid. Biochem Pharmacol 33:1273-1276

Skeggs LT, Kahn JR, Shumway NP (1956) The preparation and function of the hypertensin-converting enzyme. J Exp Med 103:295-299

Vickers C, Hales P, Kaushik V, Dick L, Gavin J, Tang J, Godbout K, Parsons T, Baronas E, Hsieh F, Acton S, Patane M, Nichols A, Tummino P (2002) Hydrolysis of biological peptides by human angiotensin-converting enzyme-related carboxypeptidase. J Biol Chem 277:14838-14843

Xun P, Hou N, Daviglus M, Liu K, Morris JS, Shikany JM, Sidney S, Jacobs DR, He K (2011) Fish oil, selenium and mercury in relation to incidence of hypertension: a 20 -year follow-up study. J Intern Med 270:175-186
Yadav S, Singh HB, Butcher RJ (2017) Synthesis and reactivity of selones and dihaloselones: complexation of selones with d8- and d10-metal ions. Eur J Inorg Chem 23:2968-2979

Yamashita Y, Yamashita M (2010) Identification of a novel seleniumcontaining compound, selenoneine, as the predominant chemical form of organic selenium in the blood of bluefin tuna. J Biol Chem 285:18134-18138

Yamashita M, Yamashita Y, Suzuki T, Kani Y, Mizusawa N, Imamura S, Takemoto K, Hara T, Anwar H, Yabu T, Touhata K (2013a) Selenoneine, a novel selenium-containing compound, mediates detoxification mechanisms against methylmercury accumulation and toxicity in zebrafish embryo. Mar Biotechnol 15:559-570

Yamashita M, Yamashita Y, Ando T, Wakamiya J, Akiba S (2013b) Identification and determination of selenoneine, 2-selenyl- $N \alpha$, $N \alpha, N \alpha$-trimethyl-L-histidine, as the major organic selenium in blood cells in a fish-eating population on remote Japanese islands. Biol Trace Elem Res 156:36-44

Publisher's Note Springer Nature remains neutral with regard to jurisdictional claims in published maps and institutional affiliations. 